\title{
Empathic people have more friends: Empathic abilities predict social network size and position in social network predicts empathic efforts
}

\author{
Peter Kardos ${ }^{\mathrm{a}, *}$, Bernhard Leidner $^{\mathrm{b}}$, Csaba Pléh $^{\mathrm{c}}$, Péter Soltész ${ }^{\mathrm{d}}$, Zsolt Unoka $^{\mathrm{e}}$ \\ a Division of Social \& Behavioral Science, Bloomfield College, NJ, United States \\ ${ }^{\mathrm{b}}$ University of Massachusetts Amherst, United States \\ ${ }^{\mathrm{c}}$ Central European University, Hungary and Collegium de Lyon, France \\ d Pázmány Péter Catholic University, Hungary \\ e Semmelweis University, Hungary
}

\section{A R T I C L E I N F O}

\section{Article history:}

Keywords:

Social network

Empathy

Social brain hypothesis

Empathic concern

\begin{abstract}
A B S T R A C T
Living in large groups and maintaining extensive social relationships, as humans do, requires special social capabilities. Past research has shown that social cognitive abilities predict people's social network size. To extend these findings we explored the role of a social emotional ability, and investigated how empathic abilities shape people's social network. In line with the social brain hypothesis the findings show that dispositional empathic abilities (IRI), and empathic concern specifically, predict how many close relationships people maintain. The study also found that emphatic abilities are strategically used in people's social network, with more empathy exercised in the support group with closer relationships. The findings further demonstrate the social function of empathy and highlight the importance of understanding empathy in terms of its strategic exercise among various social relationships.
\end{abstract}

(c) 2017 Elsevier B.V. All rights reserved.
Humans evolved living in groups. The reproductive and survival benefits that groups provided explain the basic human motivation to establish and maintain social bonds (Baumeister and Leary, 1995; Bowlby, 1969; Buss, 1990; Fiske, 2010). While living in big groups provided protection, maintaining multiple and various relationships and thus maneuvering in a complex social environment requires special abilities. Humans adapted well to this requirement. In fact, the social brain hypothesis proposes that it is for the reason of maintaining social relationships that social animals have developed large brains with specific social capabilities (Dunbar, 1993; Dunbar and Shultz, 2007). A species' social capabilities not only enable, but also limit, the number of relationships its members can maintain. Understanding and tracking others' mental states in the social environment depletes social capabilities (Dávid-Barrett and Dunbar, 2013) and building up trust and close ties require large time investment (Sutcliffe et al., 2012).

Because of time and social capabilities are finite, people allocate them strategically among their relationships in their social network. To best use their limited capabilities, the relationships in a person's social network are structured in layers. Individuals spend more time and use more their social capabilities for those

\footnotetext{
* Corresponding author.

E-mail address: peter_kardos@bloomfield.edu (P. Kardos).
}

in their support group-the network's most central layer containing the closest relationships with high contact frequency (Roberts and Dunbar, 2011). They invest less effort into relationships in the less central network layers (Sutcliffe et al., 2012), like the second network layer called sympathy group, which contains important relationships with on average monthly contact (Hill and Dunbar, 2003); the third network layer that contains less important relationships; or the fourth layer that contains the peripheral social relationships (Kudo and Dunbar, 2001; Zhou et al., 2005).

Demonstrating the relationship between social capabilities and network size, past research found that individual differences in social-cognitive abilities predict the number of relationships that people maintain. Mentalising is a social cognitive ability that allows people to correctly infer and remember others' higher-order intentions and desires. It was found that the better people are able to mentalise, the larger is their social network as well as the brain regions associated with intention-attribution (Dunbar, 2012; Lewis et al., 2011; Powell et al., 2012; Stiller and Dunbar, 2007). More specifically, people's mentalising ability predicts the size of their support groups, whereas people's memory capacity predicts the size of their sympathy groups (Stiller and Dunbar, 2007).

So far research has focused on the role that cognitive abilities and the brain regions associated with them play in predicting the number of relationships people maintain. Psychological research, however suggests that social relationships depend on both cog- 
nitive and affective capabilities. In this paper we focus on a social affective capability, empathy, the ability to understand and relate to others' affective states, and investigated if, and if so, how, it shapes people's social networks.

\section{Empathy}

People's understanding of others' mental states lays the foundation of social interactions and bonding (Theory of Mind; Frith and Frith, 1999; Herrmann et al., 2007). Both the understanding of others' intentions and attending to their emotional states are necessary for social relationships to last (Shamay-Tsoory and Aharon-Peretz, 2007). In fact, understanding others' intentions or emotions without properly reacting to them can signal psychopathic (Decety et al., 2013) or Machiavellian (Davies and Stone, 2003; Jones and Paulhus, 2009) personality disorder. Mentalising ability, for example, correlates with emotion recognition, but it does not predict performance on other empathic measures that are associated with properly reacting to those emotions, (Launay et al., 2015). The crucial capability that shapes humans' understanding of and proper reaction to others' emotional states is called empathy (Batson, 1991, 2009).

Empathy connects and unites people with each other (Davis, 2004), and provides the "social glue" (Hoffman, 2000) that holds societies together (McDougall, 1908/1923). Empathy evolved in mammalian species that live in complex social groups, facilitating bonding and cooperation (de Waal, 2009; de Waal, 2012). Importantly, people differ in their empathic abilities. The individual differences are partly due to genetic causes (Rodrigues et al., 2009) but empathic abilities can also be improved through learning (e.g. Decety and Fotopoulou, 2015).

Given the central role of empathy in social interactions (Batson, 2009), we hypothesized that individual differences in dispositional empathic abilities would explain variation in network size. Specifically, as emotional closeness and understanding is most important in the support group (vs. the outer layers), empathy should be most likely predict the size of the support group. We thus expected that people with better dispositional empathic abilities would have more relationships in their support group. In line with this hypothesis, neuroimaging studies have shown that the size of the amygdala - a brain region that plays an important role in empathic reactions (Decety, 2010; Decety and Michalska, 2010) - predicts social network size (Bickart et al., 2011).

The social brain hypothesis also suggests that social capabilities are unevenly used within one's social network. People do not invest their limited social capabilities homogeneously in their social network (Pollet et al., 2013). Instead, they exert different levels of effort to maintain relationships in the different network layers: more in the central layers (i.e. support group; Curry et al., 2012; Sutcliffe et al., 2012). As a result, people can maintain their most important relationships with high intensity (Binder et al., 2012; Roberts et al., 2009). Like menatlising, empathy has its limits too. People cannot empathize at equally high level with everyone they know, nor can they manage to feel the pain of everyone they see suffering (Cheng et al., 2007; Decety et al., 2010; Slovic, 2007). We thus predicted that people would not empathize evenly across different network layers. Because people are most motivated to maintain their intimate relationships that also should require the most empathic effort to be sustained, we hypothesized that people would exercise more empathy in relationships within their support group in particular, rather than relationships within other network layers (e.g. sympathy group).

Our prediction that people use empathy selectively to sustain some relationships over others is supported by social psychological research. While empathy is generally hardwired and automatic (Decety and Ickes, 2009; Preston and de Waal, 2002), people can still control their empathic responses (Hodges and Wegner, 1997). Strategic motivation to avoid excessive distress or negative attitudes toward the target often curtail empathic responses (Castano, 2012; Cikara et al., 2011a, 2011b; Decety et al., 2010; Dovidio et al., 2010). In other words, while people are predisposed towards empathy (e.g. Davis, 1980; Baron-Cohen and Weelwright, 2004), they modulate their predisposed level of empathy, exerting more or less empathy depending on the situation and the target person. Extending this more nuanced understanding of empathy, we predicted that people systematically vary their empathic reactions even among their close social relationships. To test this assumption, in addition to examining people's dispositional empathy as a global trait (as commonly done), we also examined their contextualized empathy directed towards different members in their social network.

\section{Method}

\section{Participants}

Eighty Americans recruited via Amazon Mechanical Turk completed the study online, using Qualtrics (Mage $=34.58, S D=11.03$, range: $19-72 ; 46$ female). The sample size was determined based on past research testing similar hypotheses with similar designs (e.g., Stiller and Dunbar, 2007). The Institutional Review Board of the first author's home institution has reviewed and approved the study.

\section{Materials and procedure}

Participants first completed a demographic questionnaire, followed by the Interpersonal Reactivity Index (IRI; Davis, 1980) as a measure of dispositional empathy. The IRI reflects the multidimensional nature of empathy, encompassing both empathic understanding of and reactions to others (Shamay-Tsoory, 2011). We administered three of the IRI's four subscales, each with seven items (IRI's fourth subscale of Fantasy, assessing the ability to imagine and experience the emotions of fictitious characters, did not pertain to our topic of interest and was not measured). The perspective taking (PT) subscale measured people's ability and tendency to view the world from others' point of view (e.g. When I'm upset at someone, I usually try to "put myself in his shoes" for a while). The empathic concern (EC) subscale measured the tendency to feel for others and react emotionally to others' misfortune (e.g. I am often quite touched by things that I see happen). The empathic distress (ED) subscale measured how well people cope with emotionally disturbing situations (e.g. I sometimes feel helpless when I am in the middle of a very emotional situation). Participants expressed their agreement with each of the 21 items, presented in random order, on a scale with the endpoints labeled Strongly disagree (1) and Strongly agree (9). An exploratory factor analysis of all items resulted in three factors corresponding to the three intended subscales. We thus averaged the seven items of each subscale into the following composite scores: perspective taking $(M=6.73, S D=1.48, \alpha=0.89)$, empathic concern $(M=6.79, S D=1.64, \alpha=0.90)$, and empathic distress $(M=3.81, S D=1.86, \alpha=0.93)$.

\section{Name generator}

To extract participants' social networks, we asked participants to list their acquaintances (so-called alters). Focusing on the central two network layers of support and sympathy group, we asked participants to list only those alters that they were in contact with at least once per month and had some sort of personal relationship with. Following others (Hill and Dunbar, 2003; Pollet et al., 2011), alters that participants were only in contact with in work environments, professionally (e.g. doctor), or briefly (e.g. mailman), were 
Table 1

Correlations between dispositional empathic abilities and the size of the central two network layers.

\begin{tabular}{|c|c|c|c|c|c|}
\hline & Support clique & Sympathy group & Perspective taking & Empathic concern & Empathic distress \\
\hline Perspective taking & $\begin{array}{l}r=0.22 \\
p=0.049\end{array}$ & $\begin{array}{l}r=-0.00 \\
p=0.990\end{array}$ & 1 & $\begin{array}{l}r=0.49 \\
p<0.001\end{array}$ & $\begin{array}{l}r=-0.19 \\
p=0.086\end{array}$ \\
\hline Empathic concern & $\begin{array}{l}r=0.36 \\
p=0.001\end{array}$ & $\begin{array}{l}r=0.06 \\
p=0.607\end{array}$ & - & 1 & $\begin{array}{l}r=0.02 \\
p=0.872\end{array}$ \\
\hline Empathic distress & $\begin{array}{l}r=0.10 \\
p=0.382\end{array}$ & $\begin{array}{l}r=0.05 \\
p=0.655\end{array}$ & - & - & 1 \\
\hline
\end{tabular}

not eligible unless they were also friends. Participants could enter a maximum of 22 names. Participants were then asked to add up to eight more names to the list, for people whom they felt emotionally close to regardless of contact frequency, as well as their parents, siblings, spouses and/or children if they had not listed them previously.

\section{Alter questionnaire}

Next, participants answered a series of questions about each alter they listed. Participants reported the alter's age, gender, how frequently they were in contact with the alter (on a five-point scale: Everyday/nearly every day; At least once a week; At least once every two weeks; At least once a month; Less then once a month), their empathy toward the alter as well as closeness to the alter. For each question, the alter's name appeared in the question text (e.g. What is the age of Henry?). Participants' empathy toward the alter was measured with three items, one for each of the three measured aspects of the IRI: alter-level perspective taking (I easily adopt Henry's point of view and imagine how I would feel in his place, $M=6.25, S D=1.51$ ); alter-level empathic concern (I often have tender, concerned feelings when Henry is having problems; $M=6.90, S D=1.49$; and alter-level empathic distress (If Henry needed help in an emergency or very emotional situation, I would probably feel distressed and anxious; $M=5.91$, $S D=2.05$ ). These items were measured on continuous analogue scales ranging from Strongly disagree (1) to Strongly agree (9). Participants' closeness to the alter (How close do you feel emotionally to Henry? $M=6.54, S D=1.54$ ) was measured on a continuous analogue scale from Not at all (1) to Very much (9).

Following others (Pollet et al., 2011; Dunbar and Spurs, 1995; Hill and Dunbar, 2003), the support group was operationally defined as the set of alters with whom participants had at least weekly contact and scored above the 80th percentile on emotional closeness. The sympathy group was defined as the set of alters with whom participants had less than weekly but at least monthly contact, regardless of emotional closeness. The hierarchical layers of the social network are commonly understood to be inclusive, meaning that the outer layers include the alters of the more central layers (but not vice versa). All alters in the support group, for example, also belong to the sympathy group, while the alters in the sympathy group do not necessarily also belong to the support group. Based on this operational definition of support and sympathy group, the mean support group size was $3.57(S D=3.06)$ and the mean sympathy group size was $8.47(S D=5.56)$, both falling into the typical range of these groups' sizes found in past research (Zhou et al., 2005). Yet, because we aimed to assess how dispositional empathic abilities predict the size of the different network layers as well as the variation of contextualized, alter-level empathic reactions in different layers, a non-inclusive, mutually exclusive operational definition of support and sympathy group was statistically more accurate for our purposes (see also Pollet et al., 2011; Roberts et al., 2008). This way, the results for the sympathy group could not be confounded with any overlap between sympathy group and support group inclusively defined. Defining the groups in this exclusive way, the mean support group size was of course identical to its size according to the inclusive definition $(M=3.57, S D=3.06)$, but the mean sympathy group size was $4.90(S D=4.22)$.

\section{Results}

Dispositional empathy as a predictor of network layer size

First we tested the hypothesis that dispositional empathy would predict the size of the support (but not sympathy) group in one's social network. Similarly to others who predicted network size based on social-cognitive capabilities (e.g. Lewis et al., 2011), we ran a correlational analysis with the three facets of dispositional empathy (IRI) and the size of the support and sympathy group. Consistent with past research on mentalising, the size of the support group was significantly correlated with perspective taking, the more cognitive component of empathy (Davis, 1980; Shamay-Tsoory, 2011), $r=0.22, p=0.049$. Importantly, however, it also correlated with empathic concern, the affective component of empathy, $r=0.36$, $p=0.001$. Empathic distress did not correlate with support group size, $r=0.10, p=0.381$. The size of sympathy group, on the other hand, was not predicted by any of the empathic abilities (see Table 1). None of the empathy sub-scales was significantly correlated with emotional closeness in the support or in the sympathy group, all $r s<0.19$, all $p s>0.10$.

Because the three types of empathic abilities correlated with each other (while multicollinearity was not present: no component contributed to more than 0.15 proportion of variation of two predictor variables), we further tested their independent effects on support and sympathy group sizes with multiple regression. Support group size was only predicted significantly by empathic concern, $\beta=0.31, t(76)=2.54, p=0.013$. It was not predicted anymore by perspective taking once the overlap between perspective taking and empathic concern and distress was accounted for, $p=0.470$. Sympathy group size was not influenced significantly by any predictor. These results also held when we additionally controlled for emotional closeness. These patterns supported our hypothesis that above and beyond more cognitive elements of empathy, dispositional empathic concern - the affective component of empathy - determines how many very close social relationships people maintain.

Table 2

Means and standard errors of the different types of alter-level empathy by network layer.

\begin{tabular}{lll}
\hline & Support group & $\begin{array}{l}\text { Sympathy } \\
\text { group }\end{array}$ \\
\hline Perspective taking & $M=0.52$ & $M=-0.27$ \\
& $S E=0.073$ & $S E=0.071$ \\
Empathic concern & $M=0.57$ & $M=-0.28$ \\
& $S E=0.073$ & $S E=0.071$ \\
Empathic distress & $M=0.34$ & $M=-0.17$ \\
& $S E=0.073$ & $S E=0.071$ \\
\hline
\end{tabular}


Table 3

$t$ values and $p$ values of the pairwise comparisons of empathy types within and between layers.

\begin{tabular}{|c|c|c|c|c|c|}
\hline & $\begin{array}{l}\text { Empathic concern } \\
\text { - support group }\end{array}$ & $\begin{array}{l}\text { Empathic distress - } \\
\text { support group }\end{array}$ & $\begin{array}{l}\text { Perspective taking } \\
\text { - sympathy group }\end{array}$ & $\begin{array}{l}\text { Empathic concern } \\
\text { - sympathy group }\end{array}$ & $\begin{array}{l}\text { Empathic distress - } \\
\text { sympathy group }\end{array}$ \\
\hline Perspective taking - support group & $\begin{array}{l}t=-0.88 \\
p=0.375\end{array}$ & $\begin{array}{l}t=3.05 \\
p=0.002\end{array}$ & $\begin{array}{l}t=9.66 \\
p<0.001\end{array}$ & $\begin{array}{l}t=9.81 \\
p<0.001\end{array}$ & $\begin{array}{l}t=8.45 \\
p<0.001\end{array}$ \\
\hline Empathic concern - support group & & $\begin{array}{l}t=3.94 \\
p<0.001\end{array}$ & $\begin{array}{l}t=10.29 \\
p<0.001\end{array}$ & $\begin{array}{l}t=10.44 \\
p<0.001\end{array}$ & $\begin{array}{l}t=9.08 \\
p<0.001\end{array}$ \\
\hline Empathic distress - support group & & & $\begin{array}{l}t=7.48 \\
p<0.001\end{array}$ & $\begin{array}{l}t=7.63 \\
p<0.001\end{array}$ & $\begin{array}{l}t=6.27 \\
p<0.001\end{array}$ \\
\hline Perspective taking -sympathy group & & & & $\begin{array}{l}t=0.25 \\
p=0.801\end{array}$ & $\begin{array}{l}t=-1.96 \\
p=0.050\end{array}$ \\
\hline Empathic concern - sympathy group & & & & & $\begin{array}{l}t=-2.21 \\
p=0.027\end{array}$ \\
\hline
\end{tabular}

\section{Contextualized empathy as a predictor of network layer size}

Next we tested the hypothesis that people distribute their contextualized empathy unevenly among the alters in their social network and exert more empathy toward the alters in their support than in their sympathy group. Here the units of observation were the alters that participants listed, and the dependent variables were the three types of alter-level empathy that participants reported to experience toward each alter (i.e., alter-level perspective taking, alter-level empathic concern, and alter-level empathic distress). We thus transposed the data so that alters were the "cases," resulting in as many cases for each participant as the number of alters they had listed, multiplied by the number of types of alter-level empathy (i.e. 3). Thus, here we used 801 observations and the transposed data set had 2007 cases. We ran a generalized linear mixed model with alter-level empathic concern, perspective taking, and empathic distress as dependent variables, type of alter-level empathy (empathic concern, perspective taking, empathic distress) as three-level within-subject factor, type of social network layer (support group vs. sympathy group) as two-level within-subject factor, and participants as random factor.

Type of alter-level empathy did not have a significant main effect, $F(2,1855)=1.23, p=0.294$. As predicted, however, type of social network layer did have a significant main effect, $F(1,67)=109.69, p<0.001$, with people exercising more empathy toward alters in their support $(\mathrm{M}=0.48, \mathrm{SE}=0.065)$ than in their sympathy group $(\mathrm{M}=-0.24, \mathrm{SE}=0.064)$. This pattern held generally true for all types of alter-level empathy: empathic concern, $t(1855)=10.44, p<0.001$, perspective taking, $t(1855)=9.66$, $p<0.001$ and empathic distress, $t(1855)=6.27, p<0.001$ (for the means and standard errors of each empathic ability in each network layer see Table 2). Adding participants' gender, age or both as predictors did not change results.

The interaction between the type of layer and the type of empathy was also significant, $F(2,1855)=11.08, p<0.001$. Empathic concern and perspective taking did not differ from each other significantly in the support group, $t(1855)=0.89 p=0.375$, or the sympathy group, $t(1855)=-0.25 p=0.806$, but every other possible pairwise comparison was significant, $t s>1.96$, $p s<0.05$, or marginally significant as for the comparison between perspective taking and empathic distress in the sympathy group (see Table 3 ). People thus exerted more empathy toward their alters in the support than in the sympathy group, with empathic concern and perspective taking being equally and primarily important in the support group, and more so than in the sympathy group. In other words, people utilize their empathic abilities in a strategic pattern to maintain their closest social relationships.

To test if the results hold if we controlled for the possible effects of the dispositional empathies, we ran again the generalized linear mixed model but now adding the three types of dispositional empathies as covariates. This left the results virtually the same.
Then we tested if the degree of the different types of dispositional empathies would qualify the reported results. For that reason, we ran again the generalized linear mixed model but now introducing the three dispositional empathic abilities (empathic concern, perspective taking and empathic distress) as three separate continuous moderator variables. None of the two-way interaction terms between the dispositional empathic abilities and the type of layers or the three-way interaction terms between the dispositional empathic abilities, the type of layers and the type of empathy was significant, all $F s<2.31$, all $p s>0.10$.

\section{Discussion}

Supporting and further extending the social brain hypothesis, the findings show that similarly to cognitive social capabilities, affective social capabilities also predict the number of core relationships in people's social networks. People with higher dispositional empathic abilities, and specifically with higher dispositional empathic concern, maintained more close relationships. This suggests that besides the ability to understand and track others' intentions and desires (Stiller and Dunbar, 2007), the ability to understand and react to others' affective states play a critical role in successfully navigating a complex social world. This held true for people's support groups in particular-that is, people's most important and intimate relationships in life. Our data indicate that the maintenance of these relationships requires, or at least benefits from, mutual emotional understanding and concern. Relationships in the outer layers, on the other hand, are less characterized with deep emotional understanding and attention. Our data show that the relationships in people's sympathy groups do not rely as much on mutual emotional understanding and concern.

In addition to contributing to research on social networks and the social brain hypothesis, the present research also contributes to psychological theory and research on empathy. First, it demonstrates empathy's functional role in maintaining social relationships and lends support to theories suggesting that empathy evolved in mammalian species as an instrument of the social brain. Further, it highlights the importance of understanding empathy in terms of its distribution among social relationships - in addition to the more common understanding of empathic abilities as a disposition or trait. While people often regulate their empathic efforts with respect to others who might cause them distress or whom they relate to negatively, the present findings show that people also regulate their empathic efforts with respect to others who are emotionally close to them, depending on the targets' position in the social network and its associated need to be emphasized with in order to maintain the relationship. Thus, it appears that people's social networks are not only determined by people's overall, trait-level empathy. They appear to be determined in a more fine-grained manner, by people's contextualized empathy for specific others in their networks. Specifically, people unevenly utilized 
their empathic ability across their social network, with more empathy going towards the closest relationships in the support group and less towards relatively less close relationships in the sympathy group. In this sense, people's dispositional empathy can be thought of as setting an overall limit to empathic abilities to maintain social relationships. At the same time, people are able to make differential, context-specific use of their empathic abilities depending on the position of any given relationship in their social network. This way, people can most efficiently use their empathic ability as the social context demands.

\section{References}

Batson, C.D., 1991. The Altruism Question: Toward a Social-Psychological Answer. Erlbaum, Hillsdale, NJ.

Batson, C.D., 2009. These things called empathy: eight related but distinct phenomena. In: Decety, J., Ickes, W. (Eds.), The Social Neuroscience of Empathy. MIT Press, Cambridge, MA, pp. 3-15.

Baumeister, R.F., Leary, M.R., 1995. The need to belong: desire for interpersonal attachments as a fundamental human motivation. Psychol. Bull. 117, 497-529

Bickart, K.C., Wright, C.I., Dautoff, R.J., Dickerson, B.C., Barrett, L.F., 2011. Amygdala volume and social network size in humans. Nat. Neurosci. 14, 163-164.

Binder, J., Roberts, S., Sutcliffe, A., 2012. Closeness, loneliness: support: core ties and significant ties in personal communities. Soc. Netw. 34, 206-214.

Bowlby, J., 1969/1982. Attachment and Loss. Basic Books, New York, NY.

Buss, D.M., 1990. The evolution of anxiety and social exclusion. J. Soc. Clin. Psychol 9, 196-201.

Castano, E., 2012. Antisocial behavior in individuals and groups: an empathy-focused approach. In: Deaux, Kay, Snyder, Mark (Eds.), Handbook of Personality and Social Psychology. Oxford University Press, New York and Oxford, pp. 419-445.

Cikara, M., Botvinick, M.M., Fiske, S.T., 2011a. Us versus them: social identity shapes neural responses to intergroup competition and harm. Psychol. Sci. 22, 306-313.

Cikara, M., Bruneau, E., Saxe, R., 2011b. Us and them: intergroup failures of empathy. Curr. Dir. Psychol. Sci. 20, 149-153.

Curry, O., Roberts, S., Dunbar, R., 2012. Altruism in social networks: evidence for a kinship premium. Br. J. Psychol. 104, 283-295.

Dávid-Barrett, T., Dunbar, R.I.M., 2013. Processing power limits social group size: computational evidence for the cognitive costs of sociality. Proc. R. Soc. Lond. B $280,1765$.

Davis, M.H., 1980. A multidimensional approach to individual differences in empathy. JSAS Cat. Sel. Doc. Psychol. 10, 85.

Davis, M.H., 2004. Empathy: negotiating the border between self and other. In: Tiedens, L.Z., Leach, C.W. (Eds.), The Social Life of Emotions. Studies in Emotion and Social Interaction. Cambridge University Press, New York, NY, pp. 19-42.

Decety, J., Fotopoulou, A., 2015. Why empathy has a beneficial impact on others in medicine-unifying theories. Front. Behav. Neurosci. 8, 457.

Decety, J., Ickes, W. (Eds.), 2009. The Social Neuroscience of Empathy. MIT Press, Cambridge, MA.

Decety, J., Michalska, K.J., 2010. Neurodevelopmental changes in the circuits underlying empathy and sympathy from childhood to adulthood. Dev. Sci. 13, 886-899.

Decety, J., Yang, C.-Y., Cheng, Y., 2010. Physicians down-regulate their pain empathy response: an event-related brain potential study. Neuroimage 50, 1676-1682.

Decety, J., Chen, C., Harenski, C.L., Kiehl, K.A., 2013. An fMRI study of affective perspective taking in individuals with psychopathy: imagining another in pain does not evoke empathy. Front. Hum. Neurosci. 7, 489.

Decety, J., 2010. To what extent is the experience of empathy mediated by shared neural circuits? Emot. Rev. 2, 204-207.

Dovidio, J.F., Johnson, J.D., Gaertner, S.L., Pearson, A.R., Saguy, T., Ashburn-Nardo, L., 2010. Empathy and intergroup relations. In: Mikulincer, M., Shaver, P.R. (Eds.), Prosocial Motives, Emotions, and Behavior: The Better Angels of Our Nature. American Psychological Association, Washington, DC, pp. 393-408.
Dunbar, R.I.M., Shultz, S., 2007. Evolution in the social brain. Science 317, 1344-1347.

Dunbar, R.I.M., 1993. Coevolution of neocortical size: group size and language in humans. Behav. Brain Sci. 16, 681-735.

Dunbar, R.I.M., 2012. The social brain meets neuroimaging. Trends Cogn. Sci. 16, $101-102$.

Fiske, S.T., 2010. Social Beings: Core Motives in Social Psychology. Wiley, New York.

Frith, C., Frith, U., 1999. Interacting minds - A biological basis. Science 286, $1692-1695$.

Herrmann, E., Call, J., Hernandez-Lloreda, M.V., Hare, B., Tomasello, M., 2007. Humans have evolved specialized skills of social cognition: the cultural intelligence hypothesis. Science 317, 1360-1366.

Hill, R.A., Dunbar, R.I.M., 2003. Social network size in humans. Hum. Nat. 14, 53-72.

Hodges, S.D., Wegner, D.M., 1997. Automatic and controlled empathy. In: Ickes, W. (Ed.), Empathic Accuracy. Guilford, New York, NY, pp. 311-339.

Hoffman, M.L., 2000. Empathy and Moral Development: Implications for Caring and Justice. University Press, New York: Cambridge.

Kudo, H., Dunbar, R., 2001. Neocortex size and social network size in primates. Anim. Behav. 62, 711-722.

Launay, J., Pearce, E., Wlodarski, R., van Duijn, M., Carney, J., Dunbar, R.I.M., 2015. Higher-order mentalising and executive functioning. Personal. Individ. Differ 86, 6-14.

Lewis, P.A., Rezaie, R., Brown, R., Roberts, N., Dunbar, R.I.M., 2011. Ventromedial prefrontal volume predicts understading others and social network size. Neuroimage 57, 1624-1629.

McDougall, W., 1923. An Introduction to Social Psychology, 18th ed. Methuen, London, UK (Original work published 1908).

Pollet, T.V., Roberts, S., Dunbar, R.I.M., 2011. Extraverts have larger social network layers but do not feel emotionally closer to individuals at any layer. J. Individ. Differ. 32, 161-169.

Pollet, T.V., Roberts, S.G.B., Dunbar, R.I.M., 2013. Going that extra mile: individuals travel further to maintain face-to-face contact with highly related kin than with less related kin. PLoS One 8 (1), e53929.

Powell, J., Lewis, P., Roberts, N., García-Fiñana, M., Dunbar, R.I.M., 2012. Orbital prefrontal cortex volume predicts social network size: an imaging study of individual differences in humans. Proc. R. Soc. Lond. B, 2157-2162.

Preston, S.D., de Waal, F.B.M., 2002. Empathy: its ultimate and proximate bases Behav. Brain Sci. 25, 1-71.

Roberts, S., Dunbar, R.I.M., 2011. Communication in social networks: effects of kinship, network size and emotional closeness. Pers. Relatsh. 18, 439-452.

Roberts, S., Wilson, R., Fedurek, P., Dunbar, R.I.M., 2008. Individual differences and personal social network size and structure. Personal. Individ. Differ. 44, 954-964.

Roberts, S., Dunbar, R.I.M., Pollet, T., Kuppens, T., 2009. Exploring variations in active network size: constraints and ego characteristics. Soc. Netw. 31, 138-146.

Rodrigues, S.M., Saslow, L.R., Garcia, N., John, O.P., Keltner, D., 2009. Oxytocin receptor genetic variation relates to empathy and stress reactivity in humans. Proc. Natl. Acad. Sci. U. S. A. 106, 21437-21441.

Shamay-Tsoory, S.G., 2011. The neural bases for empathy. Neuroscientist 17, $18-24$.

Shamay-Tsoory, S.G., Aharon-Peretz, J., 2007. Dissociable prefrontal networks for cognitive and affective theory of mind: A lesion study. Neuropsychologia 45, 3054-3067.

Stiller, J., Dunbar, R., 2007. Perspective-taking and memory capacity predict social network size. Soc. Netw. 29, 93-104.

Sutcliffe, A., Dunbar, R.I.M., Binder, J., Arrow, H., 2012. Relationships and the social brain: integrating psychological and evolutionary perspectives. Br. J. Psychol. 103, 149-168.

Zhou, W.-X., Sornette, D., Hill, R.A., Dunbar, R.I.M., 2005. Discrete hierarchical organization of social group sizes. Proc. R. Soc. Lond. B272, 439-444.

de Waal, F.B.M., 2009. The Age of Empathy: Nature's Lessons for a Kinder Society. Harmony Books, New York, NY.

de Waal, F.B.M., 2012. The antiquity of empathy. Science 336, 874-876. 